\title{
YIELD ANALYSIS OF ESSENTIAL OILS EXTRACTED BY STEAM DISTILLATION
}

\author{
Zlatin Zlatev, Galya Shivacheva \\ Trakia University, Faculty of Technics and Technologies \\ 38 Graf Ignatiev str., 8602, Yambol, Bulgaria, e-mail: zlatin.zlatev@trakia-uni.bg
}

\begin{abstract}
A comparative analysis of models describing the change in yield of essential oil over time is presented in the article. Nonlinear models, third-order polynomial and second exponential model describe with sufficient precision the change of experimental data over time. These models can be used to predict the extraction time of essential oils. The results can be useful in planning and managing the production of essential oils. For this purpose, further research is needed to determine the diffusion coefficient and to analyze the impact of the individual elements of the process on the production of essential oils.
\end{abstract}

Keywords: Essential oil, Steam distillation, Mathematical model, Rosemary, Basil, Lavender, Citronella, Dill, White oregano.

\section{INTRODUCTION}

Essential oils are used in pharmaceuticals, food and fodder production, perfumery. They are obtained by the extraction of volatile chemicals contained in most plants. Different methods are used to extract essential oils depending on the nature of the plant material and the desired properties of the product, such as distillation with water and water vapor, extraction with volatile solvents, entrainment, maceration and compression. Distillation is often used because it is simplified, convenient, with low cost of equipment working method.

According to the classification presented in the available literature [1,5], the models of the extraction process of essential oils can be divided into three categories: empirical models, liquid phase based mass balance models and solid-based models phase of the mass balance.

Various modeling strategies are used in practice, given the characteristic to be analyzed in the extraction process of essential oil. This model, which takes into account the plant's specificity in the extraction process of essential oil, is suitable [2].

The purpose of this article is to analyze mathematical models based on a solid phase of the mass balance to predict the yield of essential oil.

\section{MATERIAL AND METHODS}

\subsection{Model of extraction process of essential oils}

The extraction model was prepared according to the method presented in [3,4] and supplemented by [10]. The extraction process is diffuse. This process can be approximated by a model based on Fick's law as established and one-dimensional, by rectangular geometry. It can be assumed that the solution of plant material and water is homogeneous and consistent in composition. In the boundary areas of the vessel the evaporating water carries a small amount of essential oil and its concentration of $C_{A}$ branches to $0\left(C_{A}=0\right)$. $D$ is the diffusion coefficient. The described here may be presented as a second-order differential equation. The left part is a second derivative of $x$, and in the right part is the first derivative of time t:

IRTIIE Vol. 6, No. 4, 2018 ISSN 1314-8788 (print), ISSN 1314-8796 (online), doi: 10.15547/artte.2018.04.003 


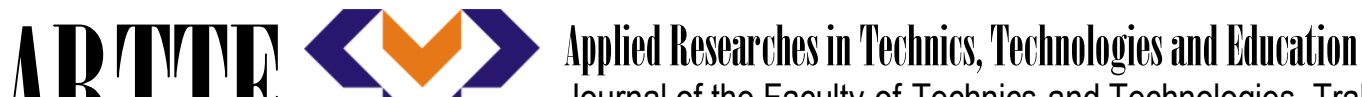 Journal of the Faculty of Technics and Technologies, Trakia University https://sites.google.com/a/trakia-uni.bg/artte/}

$$
\frac{\partial^{2} C_{A}}{\partial x^{2}}=\frac{1}{D} \frac{\partial C_{A}}{\partial t}, \text { in } 0 \leq x \leq L
$$

The initial state of the concentration at time $t=0$ is:

$$
C_{A}=C_{A_{0}} \text { in } t=0
$$

The boundary conditions for the concentration are:

$$
\begin{aligned}
& C_{A}=0 \text { in } x=0 \\
& C_{A}=0 \text { in } x=L
\end{aligned}
$$

indicating that the concentration is zero in the evaporating vapor around the walls of the vessel in which the aqueous extraction takes place.

In the case $L$ is the wall thickness of the vessel and $D$ is the effective diffusion coefficient.

The above equations are a solution to the Sturm-Liouville problem, which uses a technique for separating variables [8]. The function of the essential oil concentration relative to $x$ and the time $t$, can be expressed as:

$$
C_{A}(x, t)=\sum_{n=1}^{\infty} \frac{4 C_{A_{0}}}{n \pi} \operatorname{sen}\left(\beta_{n} x\right) e^{-D \beta_{n}{ }^{2} t}
$$

where:

$$
\beta_{n}=\frac{n \pi}{L}, n=1,2,3 \ldots \infty
$$

sen is referred to as a trigonometric function corresponding to a sinusoidal one. The mark from the original methodology of the mentioned authors is used.

The mass flow as a function of time is derived from the mass flow at the boundary multiplied by the result of the normal surface [10]:

$$
\dot{m}_{A}(t)=\frac{4 C_{A_{0}} D A}{L} \sum_{n=1}^{\infty} e^{-D \beta_{n}{ }^{2} t}
$$

The extracted mass of the soluble elements of the plant composition is:

$$
m_{A}(t)=\frac{8 m_{A_{0}}}{\pi^{2}} \sum_{m=0}^{\infty} \frac{\left(1-e^{-\frac{(2 m+1)^{2} \pi^{2} D t}{L^{2}}}\right)}{(2 m+1)^{2}}
$$

The extraction rate can be determined by:

$$
e(t)=\frac{m_{A}(t)}{m_{A}(\infty)}=\frac{\sum_{m=0}^{\infty} \frac{\left(1-e^{-\frac{(2 m+1)^{2} \pi^{2} D t}{L^{2}}}\right)}{\sum_{m=0}^{\infty} \frac{1}{(2 m+1)^{2}}}}{(2 m+1)^{2}}
$$

IRTIIE Vol. 6, No. 4, 2018 ISSN 1314-8788 (print), ISSN 1314-8796 (online), doi: 10.15547/artte.2018.04.003 


\subsection{Mathematical models}

The GNU Octave software has been used. The models are obtained with fit( $x, y$,'type') function, where $x$ and $y$ are input data, and type is the type of model. Table 1 presents the models used in the present work that are used to describe the change in time of essential oil data. Their choice is based on the more commonly used models in the available literature to describe such processes $[9,11]$.

Table 1. Models used to describe extraction processes

\begin{tabular}{|c|c|c|c|c|c|}
\hline Model name & $\begin{array}{c}\text { First-order } \\
\text { polynomial }\end{array}$ & $\begin{array}{c}\text { Second-order } \\
\text { polynomial }\end{array}$ & Third order polynomial & First exponential & $\begin{array}{c}\text { Second } \\
\text { exponential }\end{array}$ \\
\hline $\begin{array}{c}\text { Designation in } \\
\text { software }\end{array}$ & poly1 & poly2 & poly3 & exp1 & exp2 \\
\hline Linear form & $\mathrm{y}=\mathrm{a}^{*} \mathrm{x}+\mathrm{b}$ & $\mathrm{y}=\mathrm{a}^{*} \mathrm{x}^{\wedge} 2+\mathrm{b}^{*} \mathrm{x}+\mathrm{c}$ & $\begin{array}{c}\mathrm{y}=\mathrm{a}^{*} \mathrm{x}^{\wedge} 3+\mathrm{b}^{*} \mathrm{x}^{\wedge} 2+\mathrm{c}^{*} \mathrm{x}+ \\
\mathrm{d}\end{array}$ & $\mathrm{y}=\mathrm{a}^{*} \exp \left(\mathrm{b}^{*} \mathrm{x}\right)$ & $\begin{array}{c}\mathrm{y}=\mathrm{a}^{*} \exp \left(\mathrm{b}^{*} \mathrm{x}\right)+ \\
\mathrm{C}^{*} \exp \left(\mathrm{d}^{*} \mathrm{x}\right)\end{array}$ \\
\hline Formula $\mathbf{y = f ( t )}$ & $y(t)=a t+b$ & $y(t)=a t^{2}+b t+c$ & $y(t)=a t^{3}+b t^{2}+c t+d$ & $y(t)=a e^{b t}$ & $\begin{array}{c}y(t) \\
=a e^{b t}+c e^{d t}\end{array}$ \\
\hline
\end{tabular}

Table 2. Parameters for estimating the average model versus experimental data

\begin{tabular}{|c|c|c|}
\hline Parameter & Formula & Description \\
\hline $\begin{array}{l}\text { Regression } \\
\text { coefficient } R^{2}\end{array}$ & $\begin{array}{c}R^{2}=\frac{r_{s s}}{t_{s s}} \\
t_{s s}=\sum_{i=1}^{n}\left(y_{i}-y_{\text {mean }}\right)^{2} \\
r_{s s}=\sum_{i=1}^{n}\left(y_{i}-y_{i f i t}\right)^{2}\end{array}$ & $\begin{array}{l}y_{i}-\text { measured values } \\
y_{\text {mean }}-\text { average of measured } \\
\text { values } \\
y_{\text {fit }}-\text { values of the model } \\
n-\text { number of measurements }\end{array}$ \\
\hline $\begin{array}{l}\text { Sum of } \\
\text { squired errors } \\
\text { SSE }\end{array}$ & $S S E=\frac{1}{n} \sum_{i=1}^{n}\left(y_{i \text { pred }}-y_{i}\right)^{2}$ & \multirow{2}{*}{$\begin{array}{l}y_{i} \text { pred }- \text { predicted values } \\
y_{i}-\text { measured values } \\
n-\text { number of measurements }\end{array}$} \\
\hline $\begin{array}{l}\text { Root mean } \\
\text { squired error } \\
\text { RMSE }\end{array}$ & $R M S E=\sqrt{\frac{1}{n} \sum_{i=1}^{n}\left(y_{i \text { pred }}-y_{i}\right)^{2}}$ & \\
\hline $\begin{array}{l}\text { Mean square } \\
\text { error MSE }\end{array}$ & $M S E=\frac{\left\|y-y_{\text {model }}\right\|^{2}}{N_{S}}$ & $\begin{array}{l}\text { Ns - number of samples; } \| \text { - } \\
\text { normed vector }\end{array}$ \\
\hline $\begin{array}{l}\text { Normed root } \\
\text { mean squired } \\
\text { error NRMSE }\end{array}$ & $N R M S E=1-\frac{\left\|y_{\text {model }}(:, i)-y(:, i)\right\|}{\| y_{\text {model }}(:, i)-\text { mean }\left(y_{\text {model }}(:, i)\right) \|^{2}}$ & $\begin{array}{l}\mathrm{i}=1 \ldots \mathrm{n}-\text { number of } \\
\text { measurements } \\
\text { NRMSE is changed by inf - the } \\
\text { model does not describe the } \\
\text { data; } 1 \text { - the model describes } \\
\text { the data with sufficient precision }\end{array}$ \\
\hline $\begin{array}{l}\text { Normed mean } \\
\text { squired error } \\
\text { NMSE }\end{array}$ & $N M S E=1-\frac{\left\|y_{\text {model }}(:, i)-y(:, i)\right\|^{2}}{\| y_{\text {model }}(:, i)-\text { mean }\left(y_{\text {model }}(::, i)\right) \|^{2}}$ & $\begin{array}{l}\text { NMSE is changed by inf - the } \\
\text { model does not describe the } \\
\text { data; } 1 \text { - the model describes } \\
\text { the data with sufficient precision }\end{array}$ \\
\hline
\end{tabular}

IRTIIE Vol. 6, No. 4, 2018 ISSN 1314-8788 (print), ISSN 1314-8796 (online), doi: 10.15547/artte.2018.04.003 


\subsection{Model accuracy evaluation}

The GNU Octave software has been used. The ability to describe the experimental data with those of its model is done with the goodness OfFit function goodnessOfFit(y, ymodel, 'type of error') where $y$ is the experimental data, ymodel are the points of the model, type of error is the type of error, which assesses the model [7]. This function calculates a mean square error, a normalized root of a normal error, a normalized error.

In this analysis different data for essential oils is used that have not been involved in compiling the averaged models. Table 2 describes the parameters used to analyze an average model.

Data on essential oils from white oregano and dill plants was provided by the Department of Food Technology at the Faculty of Engineering and Technology in Yambol, Bulgaria $[1,6]$. Oils are obtained by aqueous extraction using a ratio of $1 / 10$ material to water. Three samples of each type of essential oil were used, the results for which were averaged.

The data obtained are compared with those for rosemary, basil, lavender, citronella, presented in $[3,4]$.

The extraction rate $\mathrm{e}, \mathrm{g} / \mathrm{g}$ according to the extraction process of essential oils is determined by the mathematical dependencies presented. Table 3 gives results for six plants.

Table 3. Change of extraction rate $(e, g / g)$ for essential oils from six plants

\begin{tabular}{|r|r|r|r|r|r|r|}
\hline $\mathbf{t}, \mathbf{m i n}$ & $\begin{array}{c}\text { Rosemary } \\
\mathbf{e}, \mathbf{g} / \mathbf{g}\end{array}$ & $\begin{array}{c}\text { Basil } \\
\mathbf{e}, \mathbf{g} / \mathbf{g}\end{array}$ & $\begin{array}{c}\text { Lavender } \\
\mathbf{e}, \mathbf{g} / \mathbf{g}\end{array}$ & $\begin{array}{c}\text { Citronella } \\
\mathbf{e , ~} \mathbf{g} / \mathbf{g}\end{array}$ & $\begin{array}{c}\text { Dill } \\
\mathbf{e}, \mathbf{g} / \mathbf{g}\end{array}$ & $\begin{array}{c}\text { White } \\
\text { oregano } \\
\mathbf{e , ~} \mathbf{g} / \mathbf{g}\end{array}$ \\
\hline 0 & 0,000 & 0,000 & 0,000 & 0,000 & 0,000 & 0,000 \\
\hline 10 & 0,810 & 0,720 & 0,490 & 0,333 & 0,111 & 0,338 \\
\hline 20 & 0,960 & 0,980 & 0,840 & 0,583 & 0,481 & 0,549 \\
\hline 30 & 0,960 & 0,980 & 0,910 & 0,667 & 0,704 & 0,775 \\
\hline 40 & 0,960 & 0,980 & 0,910 & 0,750 & 0,926 & 0,901 \\
\hline 50 & 0,960 & 0,980 & 0,910 & 0,750 & 1,000 & 0,958 \\
\hline 60 & 0,960 & 0,980 & 0,910 & 0,792 & 1,000 & 1,000 \\
\hline 70 & 0,960 & 0,980 & 0,910 & 0,833 & 1,000 & 1,000 \\
\hline 80 & 0,960 & 0,980 & 0,910 & 0,917 & 1,000 & 1,000 \\
\hline
\end{tabular}

\section{RESULTS AND DISCUSSION}

For the first four plants - rosemary, basil, lavender and citronella, data from literature sources were used, and data from the Department of Food Technologies was used for white oregano and dill. The extraction rate is set for 20 minutes for rosemary and basil. In lavender, this process is slower than the other two and has a lower extraction rate. The citronella process was not detected for the period of 80 minutes and the extraction rate slowly increased. Compared to the data on rosemary, basil, lavender and citronella, the degree of extraction for dill is found for 50 minutes, whereas for white oregano this index is set for 60 minutes.

An analysis of the yield of essential oils from the six plants under consideration was made. Figure 1 shows results for the variation of this indicator from four different plants compared to the data on dill and white oregano. 


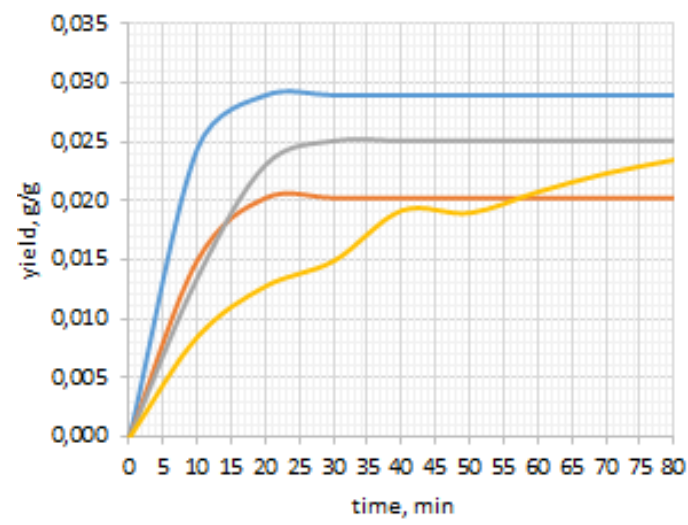

a) rosemary, basil, lavender and citronella according to $[3,4]$

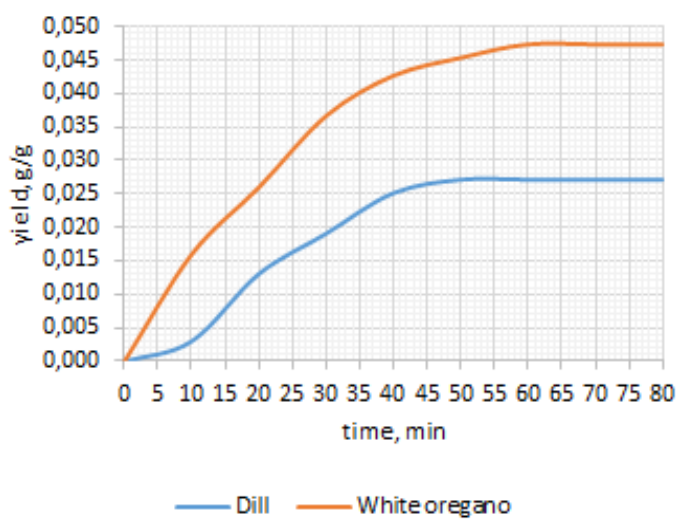

b) white oregano and dill

Figure 1. Processes of changes in the yield of essential oils

Table 4. Results of model analysis

\begin{tabular}{|c|c|c|c|c|c|c|c|c|c|c|c|c|c|c|c|}
\hline & \multicolumn{5}{|c|}{ Rosemary } & \multicolumn{5}{|c|}{ Basil } & \multicolumn{5}{|c|}{ Lavender } \\
\hline & poly1 & poly2 & poly3 & exp1 & exp2 & poly1 & poly2 & poly3 & exp1 & exp2 & poly1 & poly2 & poly3 & $\exp 1$ & exp2 \\
\hline$a$ & 0,000 & 0,000 & 0,000 & 0,019 & 0,027 & 0,000 & 0,000 & 0,000 & 0,012 & 0,018 & 0,000 & 0,000 & 0,000 & 0,014 & 0,029 \\
\hline b & 0,017 & 0,001 & 0,000 & 0,007 & 0,001 & 0,011 & 0,001 & 0,000 & 0,008 & 0,002 & 0,012 & 0,001 & 0,000 & 0,009 & $-0,002$ \\
\hline c & $\mathrm{NaN}$ & 0,008 & 0,002 & $\mathrm{NaN}$ & $-0,027$ & $\mathrm{NaN}$ & 0,005 & 0,001 & $\mathrm{NaN}$ & $-0,018$ & $\mathrm{NaN}$ & 0,004 & 0,002 & $\mathrm{NaN}$ & $-0,029$ \\
\hline $\mathrm{d}$ & $\mathrm{NaN}$ & $\mathrm{NaN}$ & 0,003 & $\mathrm{NaN}$ & $-1,156$ & $\mathrm{NaN}$ & $\mathrm{NaN}$ & 0,001 & $\mathrm{NaN}$ & $-1,133$ & $\mathrm{NaN}$ & $\mathrm{NaN}$ & 0,000 & $\mathrm{NaN}$ & $-0,079$ \\
\hline SSE & 0,000 & 0,000 & 0,000 & 0,001 & 0,000 & 0,000 & 0,000 & 0,000 & 0,000 & 0,000 & 0,000 & 0,000 & 0,000 & 0,000 & 0,000 \\
\hline $\mathrm{R}^{2}$ & 0,371 & 0,717 & 0,913 & 0,313 & 0,987 & 0,423 & 0,782 & 0,953 & 0,355 & 0,958 & 0,531 & 0,885 & 0,989 & 0,439 & 0,993 \\
\hline dfe & 7,000 & 6,000 & 5,000 & 7,000 & 5,000 & 7,000 & 6,000 & 5,000 & 7,000 & 5,000 & 7,000 & 6,000 & 5,000 & 7,000 & 5,000 \\
\hline$R^{2}$ adj & 0,281 & 0,622 & 0,861 & 0,215 & 0,979 & 0,341 & 0,710 & 0,924 & 0,262 & 0,933 & 0,464 & 0,847 & 0,983 & 0,359 & 0,989 \\
\hline RMSE & 0,008 & 0,006 & 0,004 & 0,008 & 0,001 & 0,005 & 0,004 & 0,002 & 0,006 & 0,002 & 0,006 & 0,003 & 0,001 & 0,007 & 0,001 \\
\hline MSE & 0,000 & 0,000 & 0,000 & 0,000 & 0,000 & 0,000 & 0,000 & 0,000 & 0,000 & 0,000 & 0,000 & 0,000 & 0,000 & 0,000 & 0,000 \\
\hline NMSE & $-0,695$ & 0,605 & 0,905 & $-1,565$ & 0,987 & $-0,364$ & 0,722 & 0,950 & $-1,137$ & 0,956 & 0,115 & 0,870 & 0,989 & $-0,554$ & 0,993 \\
\hline \multirow[t]{3}{*}{ NRMSE } & $-0,302$ & 0,372 & 0,691 & $-0,601$ & 0,886 & $-0,168$ & 0,472 & 0,777 & $-0,462$ & 0,791 & 0,059 & 0,639 & 0,897 & $-0,247$ & 0,918 \\
\hline & \multicolumn{5}{|c|}{ Citronella } & \multicolumn{5}{|c|}{ Dill } & \multicolumn{5}{|c|}{ White oregano } \\
\hline & poly1 & poly2 & poly3 & exp1 & exp2 & poly1 & poly2 & poly3 & exp1 & $\operatorname{exp2}$ & poly1 & poly2 & poly3 & exp1 & exp2 \\
\hline$a$ & 0,000 & 0,000 & 0,000 & 0,009 & 0,015 & 0,000 & 0,000 & 0,000 & 0,009 & 0,750 & 0,001 & 0,000 & 0,000 & 0,019 & 4,965 \\
\hline b & 0,006 & 0,001 & 0,000 & 0,014 & 0,005 & 0,004 & 0,001 & 0,000 & 0,016 & $-0,012$ & 0,012 & 0,001 & 0,000 & 0,013 & $-0,014$ \\
\hline c & $\mathrm{NaN}$ & 0,002 & 0,001 & $\mathrm{NaN}$ & $-0,015$ & $\mathrm{NaN}$ & $-0,002$ & 0,001 & $\mathrm{NaN}$ & $-0,752$ & $\mathrm{NaN}$ & 0,001 & 0,002 & $\mathrm{NaN}$ & $-4,965$ \\
\hline $\mathrm{d}$ & $\mathrm{NaN}$ & $\mathrm{NaN}$ & 0,001 & $\mathrm{NaN}$ & $-0,069$ & $\mathrm{NaN}$ & $\mathrm{NaN}$ & $-0,002$ & $\mathrm{NaN}$ & $-0,014$ & $\mathrm{NaN}$ & $\mathrm{NaN}$ & 0,000 & $\mathrm{NaN}$ & $-0,015$ \\
\hline SSE & 0,000 & 0,000 & 0,000 & 0,000 & 0,000 & 0,000 & 0,000 & 0,000 & 0,000 & 0,000 & 0,000 & 0,000 & 0,000 & 0,001 & 0,000 \\
\hline $\mathbf{R}^{2}$ & 0,860 & 0,971 & 0,990 & 0,746 & 0,994 & 0,824 & 0,978 & 0,980 & 0,673 & 0,968 & 0,807 & 0,994 & 0,998 & 0,674 & 0,997 \\
\hline dfe & 7,000 & 6,000 & 5,000 & 7,000 & 5,000 & 7,000 & 6,000 & 5,000 & 7,000 & 5,000 & 7,000 & 6,000 & 5,000 & 7,000 & 5,000 \\
\hline$R^{2}$ adj & 0,840 & 0,961 & 0,984 & 0,710 & 0,990 & 0,799 & 0,971 & 0,969 & 0,626 & 0,949 & 0,780 & 0,992 & 0,997 & 0,628 & 0,996 \\
\hline RMSE & 0,003 & 0,001 & 0,001 & 0,004 & 0,001 & 0,005 & 0,002 & 0,002 & 0,007 & 0,002 & 0,008 & 0,002 & 0,001 & 0,010 & 0,001 \\
\hline MSE & 0,000 & 0,000 & 0,000 & 0,000 & 0,000 & 0,000 & 0,000 & 0,000 & 0,000 & 0,000 & 0,000 & 0,000 & 0,000 & 0,000 & 0,000 \\
\hline NMSE & 0,837 & 0,970 & 0,990 & 0,600 & 0,994 & 0,786 & 0,978 & 0,980 & 0,396 & 0,967 & 0,761 & 0,994 & 0,998 & 0,415 & 0,997 \\
\hline NRMSE & 0,596 & 0,827 & 0,899 & 0,368 & 0,921 & 0,537 & 0,851 & 0,859 & 0,223 & 0,818 & 0,512 & 0,921 & 0,955 & 0,235 & 0,950 \\
\hline
\end{tabular}

The results of the analysis of five mathematical models describing the changes of the yield of essential oils are presented in Table 4. From this table it can be seen that the data for rosemary can be described with sufficient accuracy by a second exponential model. The yield of basil essential oil is described by third order polynomial and second exponential models. A similar result is obtained for lavender. Citronella, dill and white oregano data can be described except for both models and second order polynomial. From a practical point of view, it is good to choose a model other than a polynomial, because in some cases the model can begin to oscillate around the experimental data, resulting in unrealistic results - for example negative yields.

IRTIIE Vol. 6, No. 4, 2018 ISSN 1314-8788 (print), ISSN 1314-8796 (online), doi: 10.15547/artte.2018.04.003 


\section{CONCLUSION}

A comparative analysis of models describing the change in yield over time has been made. Nonlinear models third-order polynomial and second exponential model describe with sufficient precision the change of experimental data over time.

The models obtained can be used to predict the extraction time of essential oils. The results can be useful in planning and managing the production of essential oils. For this purpose, further research is needed to determine the diffusion coefficient and to analyze the impact of the individual elements of the process on the production of essential oils.

\section{ACKNOWLEDGEMENTS}

The research presented in this article is supported by Project 3.FTT/ 2018 "Evaluation of the Ecological Purity of Food and Raw Materials".

\section{REFERENCES}

[1] Baycheva, S. (2017). Chemical composition of oregano essential oil (Origanum heracleoticum L.), International conference of technics, technologies and education ICTTE, October 19-20, 2017, Yambol, Bulgaria, ISSN 1314-9474, pp. 410-417 (in Bulgarian)/

[2] Busato, N., J. Silveira, A. Costa, E. Costa. (2014). Estratégias de modelagem da extração de óleos essenciais por hidrodestilação e destilação a vapor, Ciência Rural, Vol. 44, No. 9, pp. 1574-1582.

[3] Cassel, E., R. Vargas (2006). Experiments and modeling of the Cymbopogon winterianus essential oil extraction by steam distillation, J. Mex. Chem. Soc., ISSN 1870249X, Vol. 50, No. 3, pp. 126-129.

[4] Cassel, E., R. Vargas, N. Martinez, D. Lorenzo, E. Dellacassa, (2009). Steam distillation modeling for essential oil extraction process, Industrial Crops and Products, Vol. 29, pp. 171-176.

[5] Dimitrova, I., N. Petkova, I. Dimov, I. Ivanov, P. Denev. (2016). Characterization of Rose Hip (Rosa canina L.) Fruits Extracts and Evaluation of Their in vitro Antioxidant Activity. Journal of Pharmacognosy and Phytochemistry, Vol. 5, No. 2, pp. 35-38.

[6] Dimov, M., S. Tasheva, K. Dobreva, A. Stoyanova. (2018). The thermodynamic diagrams for phase equilibrium of systems essential oil of dill - water and determination of height for cohobation column, Applied Researches in Technics, Technologies and Education, Vol. 6, No. 1, ISSN 1314-8796, pp. 40-44.

[7] Goodness of fit between test and reference data, https://www.mathworks.com/help/ident/ref/goodnessoffit.html (available on 30.09.2018).

[8] Kreider, D., R. Kuller, D. Ostberg, F. Perkins. (1966). An Introduction to Linear Analysis. Addison-Wesley Company Inc., Massachusetts, USA.

[9] Silveira, J., A. Costa, E. Costa. (2015). Modelagem da extração de óleos essenciais empregando coeficiente de difusão variável, Engenharia Agrícola, Vol. 35, No. 2, pp. 302-312.

[10] Silvera, J. A. Costa, E. Costa, (2017). Modeling of basil essential oil extraction with variable diffusion coefficient, Engenharia Agrícola, Vol. 37, No.4, pp. 717-726.

[11] Stefanova, R., A. Georgieva, K. Krastev. (2017). Investigation of the biologically active substances contained in forest fruits for the purpose of using them as a raw material for the production of functional beverages, Applied Researches in Technics, Technologies and Education, Vol. 5, No.4, ISSN 1314-8796, pp. 312-319.

IRTIIE Vol. 6, No. 4, 2018 ISSN 1314-8788 (print), ISSN 1314-8796 (online), doi: 10.15547/artte.2018.04.003 